\title{
Semantic Minimalism and the Frege Point ${ }^{1}$
}

\author{
HUW PRICE
}

Speech act theory is one of the more lasting products of the linguistic movement in philosophy of the mid-Twentieth century. Within philosophy itself the movement's products did not in general prove so durable. Particularly striking in this respect is the perceived fate of what was one of the most characteristic applications of the linguistic turn in philosophy, namely the view that many traditional philosophical problems are such as to yield to an understanding of the distinctive function of a particular part of language. Most typically, the crucial insight was held to be that despite appearances, the function of the part of language in question is not assertoric, or descriptive, and that the traditional problems arose at least in part from a failure to appreciate this point. Thus problems in moral philosophy were thought to yield to an appreciation that moral discourse is expressive rather than descriptive, problems in the philosophy of mind to an understanding of distinctive rôle of psychological ascriptions, and so on. The philosophical journals of the 1950s are rich with views like these. (No general term for this approach seems to have become widely accepted at the time. I shall call it "nonfactualism", for what it denies, most characteristically, is the fact-stating rôle of language of a certain kind.)

At the time, many of these non-factualist endeavours drew on the new terminology of speech act theory, taking their lead at least in part from J. L. Austin. It is therefore somewhat ironic that when non-factualism came to seen as discredited, one of the works responsible was Searle's Speech Acts. ${ }^{2}$ Non-factualism was thus disowned by the movement from which, at least in part, it drew its inspiration. So it is that while speech act theory prospered outside philosophy, its early pretensions to application within philosophy were reviled or forgotten. Non-factualism was widely thought to have fallen victim to objections urged in the 1960s by Searle, and independently by Peter Geach (who took his inspiration from an argument of Frege's).

Philosophical demise is rarely complete or permanent, however, and nonfactualism has been receiving renewed attention more recently, particularly in a

1 This is a draft of a paper which appeared in S. L. Tsohatzidis, ed., Foundations of Speech Act Theory: Philosophical and Linguistic Perspectives, London \& New York: Routledge, 1994. (The present version also includes a postscript added for the Themes from Wittgenstein conference at ANU in July 1993.) I am very grateful for comments from Simon Blackburn, Daniel Stoljar, Lloyd Humberstone and Michael McDermott, and also for the assistance of participants in seminars at Monash University and UNSW.

2 Searle 1969. Searle had earlier presented the argument in question in Searle 1962. 
relatively new application to the problem of linguistic and psychological content. ${ }^{3}$ It would now be easy for a newcomer to fail to notice that for almost a generation the approach was commonly taken to be discredited. It therefore seems worth re-examining the supposedly fatal objection. After all, perhaps non-factualism really is dead, or as dead as a philosophical view can be, and its new devotees simply haven't noticed. If not, then it would be nice to know how it managed to recover from what many took to be a mortal blow.

The paper thus begins with a brief reassessment of what I shall call the Frege argument (though I shall draw on the versions of the argument advanced by Geach and Searle). One possible outcome of this investigation would be a reaffirmation of the conclusions drawn by Geach and Searle, and thus a return to the status quo circa 1965 - perhaps an unexciting result, but a useful one, if the Frege objection succeeds, given non-factualism's current reluctance to lie down. The actual outcome is rather more interesting, however. For one thing the Frege argument turns out to be considerably less powerful than it has been taken to be, so that non-factualism remains a live option. Given the perceived importance of the Frege argument to the "overthrow" of linguistic philosophy, this conclusion suggests that contemporary philosophy might do well to reconsider. There are many contemporary metaphysical debates which would have looked sterile and misconceived to the linguistic philosophers of the 1950s. Without the Frege argument to fall back on, it would be a brave-or perhaps foolhardy - philosopher who would dismiss out of hand the linguistic point of view. ${ }^{4}$

In the present paper, however, I want to emphasise a different benefit of reexamining the Frege argument. As we shall see, the issues thereby thrown open are ones of fundamental concern in the philosophy of language and the foundations of speech act theory. In hindsight I think it is clear that when speech act theory detached itself from philosophy in the 1960s, a cluster of central issues concerning the nature of assertion, judgement, description, and the like, were left largely unresolved. I hope to show that to re-examine the Frege argument is to re-open these issues in a particularly fruitful way.

The paper is in three main parts. In the first (sections 1 to 4) I argue that the Frege argument is far from conclusive. It imposes certain constraints on the nonfactualist, but fails to show that these constraints cannot be satisfied. I shall mention work by some prominent non-factualists that went some way towards showing how their view might meet these constraints. The upshot seems to be that the worst that the non-factualist can be convicted of is a degree of complexity in linguistic theory that

3 See for example Kripke 1982; and Boghossian 1990.

$4 \quad$ For more on these themes see Price 1992. 
factualist views seem to avoid - and for all its unpleasantness, complexity is rarely a fatal complaint.

All the same, the desire to free non-factualism of this complexity motivates the second part of the paper (sections 5 to 7). This part draws on recent interest in what I here call minimal semantics, extending the terminology employed in discussions of socalled minimal theories of truth. ${ }^{5}$ Briefly, I suggest that non-factualists might (i) concede that moral claims (or whatever) are statements in some minimal sense, and use this concession to meet the requirements identified by the Frege argument in the same direct and simple way that is available to a factualist; but (ii) reformulate their point about the character of moral claims in such a way that it does not conflict with the proposition that such claims are statements in the minimal sense. The move to a minimal semantics thus enables the non-factualist to sidestep the Frege argument.

I want to suggest that in the process we achieve a fresh and illuminating view of the relationship between truth-conditional semantics and the sort of pragmatic considerations about language often thought to be the proper concern of a theory of force, or speech act theory more generally. As reformulated non-factualism directs our attention to the function of particular parts of discourse. (This functional side of nonfactualism is not new, of course; what is new is that it should be clearly divorced from a claim about the semantic status of the utterances in question.) The recognition that nonfactualism need not be a semantic doctrine then enables us to regard functional pragmatics not as an addition tacked on to deal with the problems of force and tone, but as a complement to the theory of sense whose task is to explain how there come to be uses of language with senses of particular sort-how there come to be utterances with the sense of moral judgements, for example.

True, it is not clear that the reformulated doctrine should really be called nonfactualism. As we shall see, it no longer involves the denial that the utterances of some disputed class are factual, or assertoric. Instead it treats these as relatively superficial and uninteresting linguistic categories, overlying diversity of a different kind. It is this separation of semantic and functional categories which seems to me of most interest to speech act theory. It suggests for example that assertion is a very much less

5 I first heard the term "minimal truth" from Crispin Wright, who uses it in Wright 1993; it is used in a rather different sense by Horwich 1990 . Roughly, Wright means by minimal truth the weakest notion of truth compatible with realism about an area of discourse. He takes this notion to encompass both the disquotational and normative aspects of truth, and argues that some but not all areas of discourse employ stronger notions of truth. Horwich on the other hand uses the term more or less as a synonym for the disquotational theory, and devotes his book to arguing that we don't need any stronger theory. For the purposes of this paper it won't matter whether the minimal theory is thought as embodying normativity as well as disquotation (though elsewhere I have sided with Wright in arguing that disquotation does not guarantee normativity, which therefore needs to be accounted for separately; see Price 1988, Part II). 
fundamental linguistic category than has usually been assumed. At best it is a kind of higher-order category, grouping together some very diverse linguistic activities.

All the same, the question arises as to what these diverse activities have in common, in virtue of which they all come to be part of this single higher-order category. In the third part of the paper (section 8) I conclude by drawing attention to this central issue, an issue which has tended to be overlooked in earlier work. I note that there is a sense in which the issue embodies some of the insights of the Frege argument, and hence that things are not quite so easy for my reconstituted non-factualist as they earlier appeared; but I also note that the issue is not one that the non-factualist's opponents can afford to shirk, so that the dialectical burden of the new issues is evenly spread.

\section{The Frege-Geach-Searle arguments, and Searle's unused loophole.}

The Frege argument begins by observing that non-factualist accounts characteristically propose an interpretation of just those (canonical) sentences or utterances in which constructions of the relevant type - "It is probable that ...", "It is good that ...", "It is true that ...", or whatever - are not part of any clause other than a complete sentence. It is noted that there are many other (subsidiary) occurrences of such constructions, and argued that the proposed accounts are unable to deal with at least some of these new cases, though obliged to do so. As Geach says,

Theories of non-descriptive performances regularly take into account only the use of a term ' $\mathrm{P}$ ' to call something ' $\mathrm{P}$ '; the corroboration theory of truth, for example, considers only the use of 'true' to call a statement true, and the condemnation theory of 'bad' considers only the way it is used to call something bad; predications of 'true' and 'bad' in if or then clauses, or in the clauses of a disjunction, are just ignored.

One could not write off such uses of the terms as calling for a different explanation from their use to call things true or bad; for that would mean that arguments of the pattern 'if $x$ is true (if $w$ is bad), then $p$; but $\mathrm{x}$ is true ( $w$ is bad); ergo $p$ ' contained a fallacy of equivocation, whereas in fact they are clearly valid. ${ }^{6}$

Searle's version of the argument is somewhat different, in that he admits a possibility which Geach's appeal to the validity of modus ponens would appear to exclude. Searle is objecting to what he calls "the speech act analysis" of words such as "good", "true", "know" and "probably", the general form of which he takes to be: "The word $\mathrm{W}$ is used to perform the speech act A." Searle says that

6 Geach 1960, p.223. The argument is repeated in Geach 1965. 
any analysis of the meaning of a word (or morpheme) must be consistent with the fact that the same word (or morpheme) can mean the same thing in all the grammatically different kinds of sentences in which it can occur.

For example,

the word 'true' means or can mean the same thing in interrogatives, indicatives, conditionals, negations, disjunctions, optatives, etc. (Searle 1969, p. 137)

However, Searle recognises that in order to meet this "condition of adequacy", speech act analysts are

not committed to the view that every literal utterance of $\mathrm{W}$ is a performance of A, but rather [may claim] that utterances which are not performances of the act have to be explained in terms of utterances which are. (Searle 1969, p. 138)

Searle thus appears to acknowledge that it need not be said that the contribution the clause makes to the meaning of a conditional in which it occurs as antecedent is identical to the meaning it has when used canonically; but only that the former contribution depends in a rule-governed way (the rule being associated with the conditional form) on the meaning the clause has in the latter case. If Geach's appeal to validity were successful, this view would seem untenable. The validity of modus ponens would depend on the meaning of such a clause being invariant between the two contexts.

Having admitted this possibility, however, Searle fails to take advantage of it. He rightly points out that

the speech act analysts ... need to show ... only ... that literal utterances which are not performances of the act $\mathrm{A}$ stand in a relation to performances of $\mathrm{A}$ in a way which is purely a function of the way the sentences uttered stand in relation to the standard indicative sentences, in the utterance of which the act is performed.

But he takes this to mean that if such sentences "are in the past tense, then the act is reported in the past; if they are hypothetical then the act is hypothesized, etc." He then notes the obvious, namely that "the speech act analysis of the ... words: 'good', 'true', 'probable', etc. does not satisfy this condition. ... 'If this is good, then we ought to buy it' is not equivalent to 'If I commend this, then we ought to buy it'; 'This used to be good' is not equivalent to 'I used to commend this' "; and so on. (Searle 1969, pp. 1389)

Although Searle himself does not canvas other ways in which the meaning of 
clauses such as "It is good that $P$ " in various contexts may be systematically related to their meaning when they stand alone, it is clear that if the general objection is to be answered the solution will lie in this direction. However, the argument from modus ponens claims to bar the way. Let us test its strength.

\section{The appeal to modus ponens.}

As Geach notes, this argument is due originally to Frege (Frege 1960, at pp. 129-30), who uses it in arguing that a sentential negation operator cannot be construed as a sign of force; as an indication that a sentence, when uttered, has the force of a denial. Frege's argument is in two parts:

Fr1 He notes that a negated sentence may occur as the antecedent of a conditional, where it does not amount to a denial, and concludes that in such a case the negation contributes to the sense of (or thought expressed by) the antecedent.

Fr2 He infers from this that if we want to allow that a case of modus ponens involving such a conditional is valid, we shall have to allow that the negation does not mark a denial, even when the negated sentence concerned stands alone.

The general principle invoked in $\mathbf{F r} \mathbf{1}$ is something like this:

\section{Embedded force exclusion (EFE)}

Force modifiers cannot occur in embedded contexts.

We shall come back to this, but let us first consider Fr2. Here the argument might seem to be that the validity of modus ponens depends on the meaning of the antecedent clause in the conditional premiss being exactly the same as it is when the clause occurs alone (as in the categorical premiss). It would follow that because (according to Fr1) the negative clause is not a denial in the former context, it is not a denial in the latter. But as Hare points out (Hare 1971, p. 87) the same argument would show that when the clause stands alone it does not have the force of an assertion; for it lacks this force when used as an antecedent.

A more charitable interpretation is therefore that the argument for Fr2 depends on the following claim:

\section{Sense identity (SI)}

The inference

(1) If not- $P$ then $Q$; not- $P$; therefore $Q$

is valid only if the second premiss has the same sense (or expresses the same thought) as the antecedent of the conditional premiss.

If we grant the conclusion of $\mathbf{F r 1}$-i.e., that the negation operator has a sense- 
modifying rôle in determining the meaning of the conditional premiss in (1) - then SI implies that its rôle in the second premiss must also be to modify sense. Thus as Fr2 claims, the negation operator does not modify force, even in canonical cases.

The function of the appeal to modus ponens is therefore to extend the conclusion of Fr1 to canonical uses of the negation operator (and similarly for such things as modal and ethical operators, in Geach's case). But how is SI to be justified? Not, on the face of it, by Geach's remark that otherwise the inference would contain a fallacy of equivocation. Of course, there are fallacious arguments of the syntactic form "if $P$ then $Q ; P$; therefore $Q$ " in which the fallacy turns on the fact that $P$ is used with different senses in each premiss. However, to claim bluntly that any argument of this kind is fallacious is just to beg the question (given that both sides agree that (1) is valid). For both sides agree that this claim is incompatible with the view that the two occurrences of "not- $P$ " in (1) have different senses; but the disagreement is precisely as to which of these incompatible propositions must be given up.

In any case, the use Frege and Geach make of SI depends on the principle EFE. It is EFE which underpins the claim that in the antecedent of a conditional a negation operator modifies sense. But what are the grounds for accepting EFE? Apparently just the observation that in such a context no denial is being made. But this involves the very mistake we noted in the previous section, the loophole for avoiding which is recognised (if not adequately exploited) by Searle. In effect Searle recognises that in order to make sense of an occurrence of a denial operator in an embedded context, it is not necessary to say that such a subsidiary use has exactly the meaning it has when it stands alone. It is enough that its contribution to the meaning of the containing context should depend on the fact that it does signal a denial, when used canonically. For then there is a clear reason for including a force-indicator for denial in the subsidiary positions concerned: in order to show that the clause would have this force, if uttered alone.

We saw that Searle himself does not take advantage of this loophole. But so far we have found nothing in the argument from modus ponens that provides an obstacle to others doing so. On the contrary, the appeal to modus ponens has to this point depended on the assumption that no such loophole exists.

\section{The attractions of uniformity.}

Frege and Geach do have another argument for SI, however, also appealing to modus ponens. Unlike the above argument, this one does not rely on the sub-argument Fr1. Indeed it offers an independent argument for the conclusion of Fr1 (i.e., that in the antecedent of a conditional the negation operator modifies sense). This argument begins by noting that we evidently do have identity of sense in 
and moreover that this identity of sense is clearly crucial to the validity of the argument form. It then claims that if (1) is to exemplify the same form of inference-as in some sense it surely does - then identity of sense must play the same rôle. Uniformity seems to require that there be a common account of the conditional form, in the light of which identity of sense plays a constant rôle in guaranteeing validity. Thus this is an appeal not to a necessary condition for validity as such, but to the need for a uniform explanation of the validity of a class of inferences which evidently have a structural property in common.

Such theoretical uniformity is undoubtedly desirable, but is the only way to achieve it to treat (1) as a special case of (2)? Why not instead treat (1) and (2) as distinct sub-types of a single more general form of inference? It is not obvious that in that case the general criterion for validity would include the required identity of sense. There might rather be some more general condition, which reduced to identity of sense in the special case of (2). In the next section I outline an account of this kind.

\section{Conditionals for non-factualists.}

In summary then, the task of a non-factualist who wishes to evade the Frege argument seems to be twofold: first, to find a legitimate account of the significance of a forcemodifying construction in a subsidiary clause; and second, to produce a general account of the linguistic function of the "if ... then ..." construction, such as to enable valid arguments to contain such force-modifiers in (at least) the antecedent position. The latter project is best tackled first, for the significance of a subsidiary force-modifier will inevitably depend on the nature of the subsidiary context in question. We shouldn't expect a single account, applicable to any and every subsidiary context. The individual accounts will of course have something in common, but this may be nothing more than a common reference to the meaning that the force-modifier in question has in a canonical context.

Now in arguing that the utterances of some disputed class are not genuine assertions, non-factualists commonly rely on a distinction between beliefs and others sorts of propositional attitude. With this psychological distinction assumed in place, the non-factualist argues first, that we may characterise assertion as the linguistic expression of belief; and second, that the disputed utterances express some other sort of propositional attitude. Thus Frege's opponent might tell us that negated sentences express disbeliefs rather than beliefs, the emotivist tells us that moral judgements express evaluative attitudes, the probabilistic subjectivist tells us that utterances of the 
form "It is probable that $P$ " express the speaker's high degree of confidence that $P$, and so on.

What concerns us here is not whether this is an adequate route to non-factualism in general, but the fact that by characterising force in terms of an associated type of propositional attitude, it provides the means to escape the Frege objection. The strategy requires that indicative conditionals themselves be treated non-assertorically. A sincere utterance of "If $P$ then $Q$ " will be said to indicate that a speaker possesses what may be called an "inferential disposition" - a mental state such that if the speaker were to adopt the mental attitude associated with the utterance " $P$ ", she would be led to adopt the mental attitude associated with " $Q$ ". For example the utterance "If it is not snowing, then Boris has gone swimming" will be said expresses a disposition to move from a state of disbelief that it is snowing, to a belief that Boris has gone swimming.

This suggestion provides a clear sense in which the force-modifying expression makes the same contribution to a canonical utterance, as to a conditional utterance in which it occurs in the antecedent or consequent. In each case it marks the association of the meaning of the whole utterance with a certain kind of propositional attitude: a disbelief, a degree of confidence, an evaluative attitude, or whatever. Other features of the particular occurrence of the expression in question determine firstly which particular propositional attitude of the given type is involved-its content, in other words - and secondly, how this propositional attitude stands in relation to the mental state associated with the utterance as a whole. For example in the canonical case for negation (an utterance of the form "Not $P$ ") the fact that negation is the outermost operator indicates that the mental state associated with the utterance as a whole is just disbelief itself. While in the conditional case, the occurrence of the expression in (say) the antecedent position indicates that possession of the state of disbelief in question is the antecedent condition of the inferential disposition associated with the conditional. (This process of determination may be iterated, if the conditional itself occurs as a component of some larger utterance.)

It is important to distinguish this suggestion from the claim that a conditional reports a speaker's possession of such an inferential disposition. If that were so, a conditional utterance would be an assertion about its speaker's state of mind, and would be true or false according to whether the speaker concerned actually had such an inferential disposition. However, the proposal is intended to explain the meaning of the conditional in terms not of its truth conditions but its subjective assertibility conditions-i.e., in terms of the state of the speaker that normally licences its correct use. (The term subjective assertibility condition is being used in the sense involved in saying that the normal condition for the correct use of a statement $P$ is that one believe 
that $P$. To say this is not to say that in asserting $P$ one asserts that one believes that $P .{ }^{7}$ ) The above proposal is similar to, though perhaps a little more psychologically explicit than, one made by Hare in answer to the Frege objection. Hare puts the common central insight rather nicely, saying that we know the meaning of the conditional "if we know how to do modus ponens." In other words, the crucial thing is that we are in a position to affirm "If $P$ then $Q$ " "if we know that if we are in a position to affirm $[P]$, we can go on to affirm $[Q]$." (Hare 1971, p. 87) Thus to say "If not- $P$ then $Q$ " is to indicate (though not to say) that one's state of mind is such that if one were to deny that $P$, one would affirm (or be prepared to affirm) that $Q$. The correctness of the inference (1) thus amounts to the fact that (1) is the very inference a readiness to make which is signalled by the conditional premiss; and of course the same may be said about (2). In both cases the correctness of the inference is thus analytic: the standard use of the conditional is just such as to licence modus ponens. Moreover, the rôle of the forcemodifying negation operator in the antecedent of the conditional is now clear. It helps to specify the nature of the circumstances in which the speaker indicates that she would be prepared to affirm the consequent - namely those circumstances in which she would be prepared to deny that $P$.

In Hare's form or mine, this account is of course only a beginning. Much work would need to be done to show that the notion of an inferential disposition leads to a satisfactory account of ordinary language indicative conditionals, and of simple logical inferences in which they occur. And even if the account works for conditionals, it needs

$7 \quad$ For more on this important and often overlooked distinction see for example Hare 1976 and Price 1986. On a related point, Michael Dummett once suggested that "If $P$ then $Q$ " could accommodate non-assertoric antecedents if interpreted along the lines of "If I were to assent (or commit myself) to $P$, I would commit myself to $Q$ ”. (See Dummett 1973, pp. 351-4; also Wright 1988, at pp. 31-3.) However, precisely because it confuses a plausible subjective assertibility condition for a conditional with the content of the claim concerned, it is vulnerable to the objection that in saying "If $P$ then $Q$ " one is not (necessarily) speaking about oneself. In the context of a consideration of a non-factualist interpretation of probability, this objection to Dummett's proposal was raised by Cohen 1977, p. 29, n. 19, who notes that if Dummett's reading is to apply the probability case, there should be a use for a construction

meaning "If I were to assert (agree) guardedly that $A$, then I should assert (agree) that $B$ ". But that would not be a use paraphrasable by "If it is probable that $A$, then $B$." For though it happens to be true that if I were to assert (agree) guardedly that it will be cloudy this afternoon I should also assert (agree) that I am excessively cautious in my weather predictions, it is not true that if clouds are probable then I am excessively cautious.

On the view described above, however, the conditional "If I were to assert guardedly that $A$, then I should assert that $B$ " is associated with a disposition to infer from a belief that one has asserted guardedly that $A$, to a belief that one has asserted (or will assert) that $B$. There is nothing to prevent someone from holding this disposition, but not a disposition to infer from a belief that it is probable that $A$ to a belief that $B$; and it is the latter disposition which this view associates with the conditional "If it is probable that $A$, then $B$ ". (Cohen makes the further point that on Dummett's reading there would be no obvious use for "If it is probable that $A$, then I should prefer not to assert guardedly that $A$ "; whereas there is such a use, along the same lines as "Even if it is true that $A, \mathrm{I}$ would prefer not to say so." The present view handles this in much the same way. ) 
to be extended to the many other subsidiary contexts in which (what the non-factualist regards as) force-modifying operators may occur. For each such context we need a principle which links the general linguistic function of the context itself to the working hypothesis about operators in question, namely that their independent use is to signal a non-assertoric force of some kind. Even as it stands, however, the suggested account of conditionals does serve to establish a crucial general point. To paraphrase Hare (who is concerned with the moral case, of course):

The fact that sentences containing negation cannot be described without qualification as assertions, but have to be explained in terms of the more complex speech act of denial, is no bar to the appearance of negation in contexts where denial is not taking place, provided that the relation of these contexts to those in which it is taking place can be explained. (Hare 1971, p. 93)

Hare's is not the only attempt in the literature to offer an account of conditionals with non-assertoric antecedents and consequents. I have already mentioned that of Michael Dummett (see foonote 7). Simon Blackburn also addresses the problem, again with the intention of defending a form of ethical non-factualism against the Frege argument. His suggestion is that

If it is good that $P$ then it is good that $Q$

is itself an evaluative remark: roughly, it expresses a speaker's approval of the disposition (or as Blackburn calls it the "moral sensibility") to approve of $Q$, given that one approves of $P .{ }^{8}$ Like Hare's theory and mine, this account has the crucial feature that it makes the significance of an embedded force-modifier dependent on but not identical to the significance it has in a canonical context. That said, however, it seems to me that Blackburn's account is less plausible than the approach sketched above. It has the disadvantage that it does not give us a single unified account of conditional utterances, from which the required account of conditionals with embedded moral clauses falls out as a special case-conditionals in general are not expressions of moral sensibility. I suspect that Blackburn has confused two notions of endorsement, the first the semantic endorsement we give to any proposition when we assent to it, and the second the peculiarly moral endorsement we give to an act or state of affairs of which we approve. It is arguable that assent always involves an evaluative or normative element. To assent to a proposition is to take it to be right, correct, true. But this simply means that assent to an ethical proposition involves two sorts of evaluative attitude. To agree that war is evil is to take the proposition "War is evil" to be correct, to endorse it 
in that sense; and it is also to express one's disapproval of war. With these notions of endorsement kept distinct, however, there seems no reason to say that accepting a moral conditional necessarily involves anything more than semantic endorsement. It need not itself express a moral attitude, even though it may indicate a certain structure of dependencies between the speaker's moral and non-moral attitudes. "If all war is evil then the Gulf War was evil" is merely a logical truth. ${ }^{9}$

\section{The minimal turn.}

Thus it seems that the Frege argument is less powerful than in appeared to be. It certainly isn't watertight, and considerable work has been done towards showing how its weaknesses may be exploited. All the same, there does seem to be at least one charge that will survive these ingenious attempts to evade the Frege argument. Even if they succeed, it will be at the cost of considerable theoretical complexity. It is doubtful whether this counts as an argument against the views that require this expenditure, but it is a valid expression of regret-regret that we cannot have the simplicity of the standard account. If only we could justly retain familiar platitudes about validity, truth-functional connectives, and the like, without cutting ourselves off from the insights of nonfactualism.

Well, perhaps we may. An optimistic hint is to be found in recent interest in minimalist notions of truth. At one point in his recent book on minimal theories of truth, Paul Horwich notes that such a notion of truth is not incompatible with such metaethical positions as emotivism, provided of course that the emotivist doesn't insist on trying to characterise her view of moral judgements in terms of truth; for in this case the minimal notion won't bear the weight. ${ }^{10}$

In the present case, this suggests that we might extend the minimalist notion of truth to a minimalist notion of statementhood. A (minimal) statement will simply be any utterance of which it makes sense to say that it is (minimally) true-in other words, in effect, any sentence which provides a well-formed substitution into the context "It is true that $P$." Now surely emotivists and other non-factualists cannot have been denying that certain classes of indicative sentences are statements in this minimal syntactic sense; they had some stronger thesis in mind (albeit perhaps a thesis they would have

9 Blackburn returns to the issue of conditionals with moral antecedents in Blackburn 1988. He there distinguishes two possible approaches to the problem, one ("slow track quasi-realism") in keeping with his own earlier approach, and one ("fast-track quasi-realism") more similar to the approach suggested below. He argues that the two approaches are less dissimilar than they appear at first sight. I agree, but suspect that what the fast track yields when localised to the moral case is not Blackburn's version of the slow track but something closer to Hare's.

10 Horwich 1990, at pp. 87-8. A similar train of thought has sometimes been used as an argument against non-factualism; see for example McDowell 1981 and Wiggins 1976. 
couched in terms of a stronger notion of truth). So there is evidently room for a simple compromise in response to the Frege argument. If the Fregean will concede that the ordinary platitudes about validity, truth-functional connectives and the like may appeal to nothing more than a minimal notion of truth, then the non-factualist will be entitled to endorse these platitudes at face value, and won't have to embark on the evasive manoeuvres whose complexity gave us cause for regret.

Both sides may resist this compromise on the grounds that they find the minimal notions of truth and statementhood unattractive. As noted, the non-factualist may want to characterise her position in terms of a stronger notion of truth; while the Fregean may feel that the minimal notion is inadequate for the purposes of logical and semantic theory, including that of accounting for the validity of inferences such as modus ponens. I don't want to try to address these concerns directly in this paper. ${ }^{11}$ Instead I want to sketch the form that non-factualism might take if it endorses this compromise, and thus to show indirectly that the compromise is one that it might happily live with. I also want to indicate some of the character of the minimalist semantic theory which would accompany the compromise-in particular, to indicate some respects in which it differs from orthodox Fregean semantics.

\section{Facts and linguistic functions.}

Suppose that we accept that moral judgements are minimally descriptive, meaning by this that they can be said to be minimally true and false. How might we then formulate a non-factualist doctrine concerning such judgements?

We might appeal to psychology, saying that moral claims do not express beliefs, but rather evaluative attitudes. The immediate trouble with this is that our minimal notion of statementhood will bring with it a minimal notion of belief: a minimal belief will be simply the sort of propositional attitude expressed in a minimal statement. So we need a substantial belief-evaluative attitude distinction. It would be better to talk of a special kind of belief, here using belief in its minimal sense. The resulting position would then amount to the psychological equivalent of the following view.

Let us begin with the platitude that language serves many different functions. It is easy to agree on this, but more difficult to decide how to carve things up-what the various functions of language actually are, or indeed what is meant by a function in this context. It is very tempting to think that one of the main functions of language, perhaps indeed the primary one, is that of description, or the making of factual claims. I want to

11 In Price 1988, Ch. 2, I argue at length that non-factualism cannot be satisfactorily grounded on a notion of truth; while Horwich 1990 responds to the claim that the minimal notion of truth is inadequate for various theoretical purposes. 
urge that we resist this temptation, and instead regard this particular functional category as an artificial one, imposed by the structure of language itself. I want to suggest that its apparent unity and cohesiveness is superficial, and overlies considerable diversity. To use an analogy I have appealed to elsewhere, I want to suggest that the functional category of description is like that of manual tasks. What manual functions have in common is essentially that they are all performed or capable of being performed by hand - from a biological point of view the right thing to say is not that the hand has evolved to perform tasks of a single functional category, but that the functional category consists of a diverse assortment of tasks which happen to be thrown together in virtue of the fact that all are or can be performed by that accident of evolution, the human hand.

I shall use the term "minimal description" for any utterance which is capable of being minimally true or false. The suggestion is thus that within the class of minimal descriptions, we may find sub-classes of utterances serving a range of different linguistic functions. (These sub-classes will overlap, of course, when sub-sentential constructions serving different functions are combined in a single utterance.)

Let us now suppose that one of the functions served by some minimal descriptions is that typified by ordinary and (perhaps more contentiously) scientific description of the physical world. Crudely, we might say that the function of this part of language is to signal the presence of certain conditions in the physical environment of a speaker. There would be a number of problems if we tried to make this more precise. For one thing, it would be hard to resist the slide into the semantic language of facts, states of affairs, and so on, which would soon lead us back to the very position from which we are attempting to distance ourselves, namely that the function concerned is that of minimal descriptions as a whole. For another thing, the limits of the "physical" are ill-defined in a number of relevant ways. Do we count such things as dispositions, for example, or does their modal character already exclude them?

Precision will not be critical, however. The important thing is that the nonfactualist should be able to mark some distinction between the function of (say) moral discourse, on the one hand, and the function or cluster of functions of at least a significant part of non-moral discourse, on the other. It will simplify things to assume that there is a single well defined linguistic task with respect to which this contrast may be drawn - let us call it the task of physical signalling, or natural description - but the thesis could quite well be formulated in more general terms.

Given this simplifying assumption, we thus have a distinction between the semantic (or perhaps better, syntactic) notion of minimal description, and the functional notion of natural description (or physical signalling). My suggestion is then that the non-factualists' central thesis may be thought of as the claim that in certain cases we 
systematically confuse minimal descriptions for natural descriptions. Moral judgements (or whatever) are minimal descriptions, but are not natural descriptions. Rather they serve some quite distinct linguistic function.

To what extent is this suggestion compatible with the sorts of things that nonfactualists typically say? In one sense an emphasis on misconstrual of linguistic function is a core component of any non-factualist thesis. Before all else, nonfactualism is the doctrine that utterances of a certain kind are systematically misconstrued (with significant philosophical consequences). However, the functional point is usually put in terms of semantic categories - a fact-stating-non-fact-stating distinction, or something of the kind. In other words the relevant functional divide is thought of in semantic terms. But on the present account the non-factualist's point becomes purely functional, the semantics on both sides of the distinction being agreed to be of the minimal sort. However, it seems to me that this shift makes surprisingly little difference to the philosophical force of the non-factualist move-the relevant philosophical consequences are much the same. A naturalistic reduction of moral properties is ruled inappropriate for the standard reason, for example (namely that it misconstrues the linguistic rôle of moral judgement ).

Let us see how this goes in a little more detail. Consider emotivism. The emotivist typically says that moral claims express evaluative attitudes rather than beliefs. This is compatible with the suggested gloss so long as we make a distinction between minimal belief and natural belief, paralleling that between minimal description and natural description (physical signalling). For then the emotivist may be seen as making the point that moral claims express evaluative attitudes, and that although these are (of course) minimal beliefs, they are not natural beliefs. (Their function does not lie in matching a subject's mental state to states of the physical environment, as we might put it.) This claim will do the usual work of defusing philosophical concerns about the nature of moral facts. The question as to the real nature of a state of affairs referred to by a description is one that may properly be raised in naturalistic terms if the description concerned is a natural description - in this case it is a matter which may be investigated in scientific terms. But if all we have is a minimal description (or indeed if we are considering a natural description from the minimal semantic standpoint), then such a question involves a kind of category mistake. The only possible answers are the sorts of platitudes associated with the minimal notion of truth.

Let me mention two concerns to which this proposal might give rise. One is that on this view there would be seem to be no difference between non-factualism about moral discourse and a certain form of moral realism, namely the view that although there are moral facts and states of affairs, these are not part of the natural world, and are not reducible to natural or physical facts. (In a similar way, the objection would be that 
non-factualism about psychological ascriptions could not be distinguished from certain forms of dualism.) I think that this is a very important objection, requiring much more attention to do it justice than I can give it here. Briefly, my view is that the objection tends to backfire, in the sense that its effect is to undermine the credentials of such nonreductive realisms. Against a background of minimal semantics, I think that these positions become impossible to distinguish from the (Wittgensteinian?) form of pluralism which embraces the possibility that language comprises a multiplicity of different kinds of discourse. True, non-factualism is also drawn in this direction, but I think it fares rather better, being able to cash its concern with the different degrees of objectivity of different discourses in other terms. ${ }^{12}$

The second concern is more closely related to the issues with which we began. Non-factualism is often characterised in terms of the neo-Fregean conception of the structure of a theory of meaning. That is, the non-factualist can often be represented as claiming that a certain sentential construction is mistakenly thought to modify the sense of a sentence in which it appears, whereas in fact it modifies the force. The clearest example is again provided by the denial interpretation of sentential negation, which Frege himself was attacking in his original presentation of the Frege point. ${ }^{13}$ What happens to this appealing characterisation of non-factualism, if non-factualism is presented in the way I have suggested? This question deserves a section to itself.

\section{Sense, force and function in minimal semantics.}

The above concern may be focussed by the following train of thought. Advocates of minimal truth have emphasised its affinity with Tarskian truth theories, and the truththeoretic approach to a theory of meaning. (Conversely, the "minimalism" of the truththeoretic notion of truth had already been emphasised by writers such as McDowell. ${ }^{14}$ )

12 See Price 1992, and Price 1988, Part II; also Wright 1988, 1993.

13 It may seem odd to speak of the denial interpretation of negation as a example of non-factualism. As Lloyd Humberstone puts it (in correspondence), "there seems to be a striking discontinuity between the traditional fare of ... non-factualism, and the force-based treatment of negation. No one has ever advanced a non-factualist thesis with respect to negative statements." It is true that some versions of non-factualism would have had trouble incorporating the denial view of negation. A position characterised in terms of possession of truth conditions will have its work cut out to maintain that Not- $P$ is not simply true when $P$ is false and false when $P$ is true, for example. The grouping of the denial view with other forms of non-factualism looks much more natural if couched in terms of a Fregean force-sense distinction, however - the common claim being that certain utterances lack assertoric force. It seems to me that Humberstone's "discontinuity" is really a matter of degree, the relevant variable being the ease with which truth and falsity are extended to utterances having the non-assertoric force in question. In the case of negation the bipolarity of truth and falsity guarantees that the extension is very easy indeed.

See particularly McDowell 1981. 
But doesn't this mean ${ }^{15}$ that if non-factualists endorse minimal truth they become factualists? In the resulting theory of meaning utterances of the form "Not- $P$ " have assertoric force, for example.

The non-factualist's response must be to accept the conclusion but to deny that it has the significance the objector is claiming for it. The crucial point is that on the minimal interpretation the conclusion is not incompatible with the non-factualist's positive theses about the significance of (here) negation. For the non-factualist about negation need not renounce the view that its primary rôle in language is to provide a universal means of indicating that one is dissenting from some particular proposition; or to put it psychologically, the view that negation is associated with the expression of disbelief. It is just that the non-factualist also now remarks that this activity of denial is the sort of linguistic activity which fruitfully comes to be couched in terms of the minimal notion of truth; and thus becomes an assertion, in the minimal semantic sense.

It is worth noting in passing that this opens the way to a considerably more plausible view of negation than is available to the opposition. In accepting Frege's criticism of the denial interpretation of negation, Geach appreciates that it commits him to the view that disbelief must be thought of as "belief that not". He says that

believing, like seeing, has no polar opposite. ... The distinction of 'pro' and 'contra', of favourable and unfavourable attitude, has its place only in the realm of appetite, will, and passion, not in that of belief; this shows the error in treating religious beliefs as some sort of favourable attitude toward something. (Geach 1965, p. 455)

Setting aside Geach's passing defence of religious factualism, let us consider the effect of this position on our understanding of the meaning of negation. All sides will agree that $P$ and Not- $P$ are not jointly acceptable, at least in the sense that there would normally be some serious mistake involved in assenting to both. How is the Fregean to account for this striking feature of negation? The obvious suggestion might seem to be that it results from the fact that in virtue of the truth-functional analysis of negation, $P$ and Not-P cannot both be true: if $P$ is true then Not- $P$ is not true, and vice versa. As it stands this gets us no further, however, for the original issue simply re-emerges with respect to the pair " $P$ is true" and " $P$ is not true" (or "Not( $P$ is true)"). It might seem to be an improvement to note that if $P$ is true then Not- $P$ is false, but this simply avoids one difficulty at the expense of another. It now needs to be explained what it is about truth and falsity in virtue of which one would be ill advised to assent to a pair of propositions so related. It is no use saying simply that in virtue of their opposite truth 
values the two sentences in question are "incompatible" or "inconsistent", for then the question will be why incompatibility itself matters; why the rational speaker should take pains to avoid it, among the utterances to which she assents.

The moral of all this is that the notion of incompatibility involves an intrinsic bipolarity: it takes two to tango exactly out of step, so to speak, and these two must fail to hit it off in a very special way. At some point in the Mind-Language-World triangle, this incompatibility must make its appearance. Philosophers who are sufficiently thickskinned may be inclined to accept a primitive bipolarity at some point on the Languageto-World side of the triangle; perhaps a primitive opposition between truth and falsity, or a primitive exclusion relation between negative and positive facts. In either case they then have the task of relating this piece of metaphysics to psychological and linguistic practice. In effect, they have to explain how speakers become aware of this relation of incompatibility that obtains in the world, link it to their understanding of negation, and hence display the appropriate caution in avoiding judgements of the form " $P$ and not$P ”$.

Things are much simpler if we start at the psychological corner. We don't need negative facts or a mysterious primitive opposition between truth and falsity, but merely an appreciation of the situation we face as creatures whose behaviour is determined, in part, by what we may loosely call commitments - changeable behavioural dispositions of various kinds. The premiss in the background here is a very simple one: if a creature is to meet the future with anything more than the tools it was born with, it needs the ability to prepare itself in the light of past experience. Plausibly, it is a feature of any reasonably complex system of behavioural dispositions of this kind that the states concerned may conflict, in the sense that they move their bearer in different behavioural directions. To avoid behavioural chaos, any creature capable of such commitments thus needs to be able to remove commitments from its current store, as well adding new ones. In particular, it needs to able spot conflicts before they are manifest in behaviour, and to adjust its commitments accordingly. It needs to be able to reject one commitment in the light of another.

This act of rejection is functionally distinct from the simpler act of endorsement (the act of adding a commitment to one's current store). More importantly, its functional relationship to the simpler act embodies the incompatibility we were looking for. (The impossibility of simultaneously rejecting and endorsing a given commitment is much like that of entering and leaving a room at one and the same time.) It follows that if negation is explained as initially a sign of denial, and denial as the linguistic expression of rejection, then we shall be have some prospect of explaining just what goes wrong with an attempt to endorse both $P$ and Not- $P$.

In sum, we may say in answer to Geach that although strictly speaking he is 
right to say that belief is not bipolar, in that we can make sense of commitment without the possibility of its polar opposite, a consideration of the functional rôle of belief makes it plain that the ability to reject commitments is crucial to all but the simplest believers. In order to be useful, judgement must thus become bipolar-commitments must be rejected as well as endorsed - at a very early stage. And in this we have the beginnings of an explanation of a fact about language that otherwise remains primitive and mysterious, namely the incompatibility of an assertion and its negation - an explanation which turns on the hypothesis that the primary rôle of negation is to indicate denial, or to express disbelief. ${ }^{16}$

The suggestion is that negation thus begins life as a force modifier, indicating a linguistic move of a different pragmatic significance - a different functional rôle - to anything in the language so far. Once incorporated, however, utterances with this new significance are appropriately subject to the same operations as those of the old. If this suggestion seems puzzling, the following analogy may be helpful. Negative integers are initially introduced via a quite new operator, which is applied to positive integers to yield mathematical entities of a new kind-entities which are not numbers in the previously recognised sense. The existing operations (addition, etc.) extend in a natural way to these new entities, however, with the result that they too come to be thought of as numbers. Adopting the symbolic convention that symbols referring to numbers are of the form "[...]", the ordinary expression "-2" may therefore be parsed more explicitly either as "-[2]" or as "[-2]", depending on whether we have decided to treat the products of the operation denoted by the minus sign as themselves comprising numbers. There is no single correct parsing here, merely alternative ways of representing the same thing. The only substantial question is why it is that -[2] is the sort of thing that may be regarded as a number, in some natural extension of the previous usage - to which the answer lies in the availability of natural extensions of the arithmetical operations to the members of the broader class. (Is there a corresponding question in the semantic case? We shall see below that there is.)

In the case of negation the upshot is that we do not have to make a choice between the view that negation indicates denial (or expresses disbelief) and the view that it indicates an assertion with negative content (or expresses such a belief). We may say both things, so long as we are dealing with a suitably minimal notion of belief. Disbelief or dissent comes first, for it is such a notion, cashed in functional terms, that accounts for the presence and utility of negation in the first place. But given that this

16 For more on the advantages and complexities of this, see Price 1990. However, the present account (in terms of the need for a procedure for rejecting commitments) now seems to me both simpler and more forceful than the corresponding argument in my earlier paper. 
expression of disbelief takes the minimal assertoric form, we may think of it as the expression of belief.

Putting it in Fregean terms, we might say that the sense-force boundary is not unique - we may have two (or more) ways to parse a given utterance. "Not- $P$ " may be thought of both as a denial of the proposition that $P$ and as an assertion of the proposition that not- $P$. The pragmatic account of the function of denial is not a separate component of a theory of meaning from the theory of sense, but a sub-theory, whose task is to explain how there come to be sentences with senses of a particular sort-how there come to be sentences with the sense of negative judgements, for example.

The two parsings engage with two different aspects of a theory of meaning. The platitude that to know the meaning of a sentence is to know the conditions for its correct use has two importantly different readings (not always properly distinguished). It may be taken to refer to what I earlier called subjective assertibility conditions, so that it amounts to the claim

(4) To know the meaning of "It is snowing" is to know that it is normally appropriate to say "It is snowing" only when one believes that it is snowing.

Or it may refer to truth conditions, so that the claim is that it is correct to say "It is snowing" if and only if it is snowing; or, in the more familiar form, that

"It is snowing" is true iff it is snowing.

These claims are not incompatible, of course, and knowledge of meaning surely involves knowledge of both kinds. (5) has the form we expect of the theorems of a content-specifying truth theory - a systematic specification of the meanings of the sentences of an object language by means of sentences in the home language. As has often been emphasised, this enterprise needs only a thin notion of truth. It therefore applies uniformly to all minimally descriptive parts of the object language.

Principle (4) on the other hand has the resources to cope with the functional perspective, which is crucial to the proposed reformulation of non-factualism. We may say for example that

(6) To know the correct use of "Not- $P$ " is to know that it is normally appropriate to say "Not- $P$ " only when one disbelieves that $P$.

Note that this is not incompatible with the following instance of (4):

(7) To know the meaning of "Not- $P$ " is to know that it is normally appropriate to say "Not- $P$ " only when one believes that not- $P$. 
Interpreted in terms of minimal belief, (4) is true of all minimal descriptions. But it is (6) which captures what is distinctive about utterances of the form Not-P.

In summary, then, the proposed reformulation of non-factualism encounters no special problems with respect to the goals of a theory of meaning. To the extent that such goals are met by a content-specifying truth theory, the reformulated view coincides with the standard account; while to the extent that such a truth theory needs to be supplemented by theses of the form of (4), this form is flexible enough to accommodate the functional perspective adopted by the reformulated view.

\section{Conclusion: explaining assertion.}

At the beginning of the paper I suggested that the interest in a re-examination of the Frege argument lay not simply in its immediate bearing on the viability of nonfactualist approaches to various philosophical topics, but also in the fresh perspective it promised to provide on some neglected issues in the philosophy of language and speech act theory. As we shall see, the latter benefit depends in part on an important qualification concerning the former. The path for non-factualism is not quite as smooth as the above account might suggest; and in its bumps lie the real nuggets for those interested more in language itself than in its philosophical applications.

To recap, I have suggested that non-factualism is best served by a strategic retreat, followed by an advance on new grounds. Non-factualists should concede that they put their view in the wrong way - viz. in semantic terms. What they should have said was that the mistake they opposed was that of reading substantial metaphysical conclusions into semantics. Conceding semantics is no significant loss, for the semantic ice is really too thin to support either party. While the non-factualists' intuitions concerning the distinctive rôle of (say) moral discourse are best cast in functional rather than semantic terms.

As noted earlier, there is an issue as to whether the resulting position should really be called "non-factualism". Non-factualists may be well advised to surrender their banner, as well as their untenable semantic position. In one sense this is a relatively insignificant change. The view retains the resources to combat many of the non-factualist's traditional opponents. In the moral case, for example, it remains opposed not only to the metaphysical realists who would populate the world with mysterious moral facts and properties, but also to those who in fleeing this metaphysical nightmare, turn in preference to eliminativism or naturalistic reductionism. Non-factualists always stood opposed to all these choices, and may continue to do so under this new banner.

All the same, there are some respects in which orthodox non-factualists may be discomforted by the new arrangements. Non-factualists are accustomed to riding with 
anti-realists, even if in some cases uncomfortably so. Under the new scheme their natural allies are realists, albeit of a non-metaphysical sort. Reconstituted nonfactualists will find themselves sympathetic with the minimalist realism of writers such as Wittgenstein, Davidson and Rorty (although as I point out in (Price 1992), the reconstituted view improves on these minimalist accounts in one crucial respect, namely that it directs our attention to the issue as to what different parts of language are for).

The contemporary writer whose views are closest to those of my reconstituted non-factualist is perhaps Simon Blackburn. Blackburn begins with the Humean idea that we project our attitudes and prejudices onto the world, and so see it as populated by seeming facts of our own construction. He then goes on to argue that such a nonfactualist can explain our conversing as if there really were such facts - in other words, that the Humean "projectivist" is entitled to a notion of truth, and to the other trappings of a realist linguistic practice. Thus projectivism supports "quasi-realism", as Blackburn calls it. ${ }^{17}$ On this view moral discourse (or whatever) is not really factual, but has - and is entitled to-the trappings of factuality.

One aspect of these trappings is the ability to be usefully embedded in conditional contexts, and as we noted in section 4, Blackburn has offered an account of what moral statements are doing in such contexts. We saw that in appealing to secondorder evaluative judgements, Blackburn's account could be criticised for absorbing too much of the general character of the conditional form into peculiarities of the moral case.Viewed in the light of our appeal to minimal semantics in answer to the Frege point, Blackburn's approach may also seem unnecessarily complicated. In defence of Blackburn, however, it should be conceded that the quasi-realist program embodies an insight which is in danger of getting lost in the rush to embrace minimal semantics. Not all linguistic functions are such as to be usefully cast in terms of truth and falsity, however minimally these are conceived. Someone who wants to be pluralist about underlying linguistic functions thus owes us an account of what the truth-bearing form achieves in language, and hence an explanation, case-by-case, as to why various disparate functions should invoke it. In so far as conditionals are associated with the truth-bearing form, for example, we need to be told how the general function of the conditional serves the specific purposes of moral discourse, modal discourse, or whatever.

This may sound like the difficult case-by-case work we tried to avoid in invoking minimal semantics. Have we therefore advanced at all by means of this long detour? It seems to me that from the non-factualist's point of view the situation has

17 See in particular Blackburn 1984. 
improved in one crucial respect: the question as to the general function of the truthbearing form of language has now been raised as an issue that all sides need to address. Previously, in couching their views in semantic terms, the non-factualists effectively conceded to their opponent the latter's right to an unexamined notion of the genuinely factual (or truth-bearing) use of language. The explanatory onus thus lay almost entirely on the non-factualists' side. The new approach distributes the burden much more fairly. True, the non-factualists' opponents may not have noticed that there is a general question to be raised concerning the rôle of truth-bearing constructions in language; but this is hardly a point against non-factualism. In effect, the point is that the complexity which bothered us at the end of section 4 is not a burden for non-factualism alone. The appeal to semantic minimalism does not evade this complexity, for the difficult explanatory issues remain; but it does ensure that the burden is properly spread, and that all sides take their fair share of the load.

It is here that we find the promised theoretical dividend. In responding to the Frege point in the above terms, the non-factualist draws our attention to the existence of a degree of structural complexity in language that we otherwise might have little reason to notice. Our attention is drawn to the possibility that the apparent uniformity of assertoric or declarative discourse may well mask a multiplicity of different functions. More importantly still, this model of common form over diverse function raises the issue as to what the common form is for-what it does in the service of these diverse functions. Until the non-factualist pressed a case for diversity, we had little reason not to be satisfied with a very simplistic conception of assertoric discourse-roughly, the view that it serves to make descriptive claims, to "state the facts" as the speaker believes (or claims to believe) them to be. There are other formulations of this conception, of course, but they all take for granted that what is being at least gestured at is a single reasonably coherent linguistic function. The suggested defence of nonfactualism gives us reason to question this assumption. The reconstituted non-factualist will argue that the usual formulations have little or no explanatory value, but simply rehash the same bundle of superficial idioms: "fact", "truth", "reference", "statement", "belief", and the rest. A genuinely illuminating account would be one which explained the existence of these concepts and idioms (or at least those of them which are in ordinary use) in terms of their contribution to the functions of language more basically construed. The new non-factualist points out that there is an important sense in which such an account need not be monistic - the same tool may do many jobs.

To conclude, the most central issue to which the above considerations direct our attention seems to me to be this one: What does assertoric discourse do for us? It is possible to distinguish a number of sub-issues here. What are the concepts of truth and falsity for? (What function do they serve in the lives of a linguistic community?) What 
is the significance of the linguistic constructions that apparently depend on truth-conditionals, for example? Again, how does it help us to have them? And is there a category of genuine judgements, as opposed to commitments more generally? ${ }^{18}$

In order to address these issues, it is necessary for us to take a detached explanatory stance towards our own linguistic practice. We need to step back from our familiar concepts and practices in order to be able to see the broader picture, and hence to discern the rôle that the concepts and practices concerned play in our lives. To a degree this detached perspective comes easily to non-factualists, who are accustomed to arguing that language is misleading at close range. It should also come easily to speech act theorists, for they too are used to dissecting out the hidden functions of language. However, the main point I want to urge is that by and large, neither group has stepped back far enough. Both camps have tended to regard the linguistic categories of assertion, description and the like as part of the bedrock - as a firm foundation on which other work may rest. Hence they have failed to see the importance of subjecting these categories themselves to explanatory scrutiny. In my view the great theoretical significance of the Frege point is that it directs our attention to these long neglected issues.

\section{Postscript: implications for reductive metaphysics.}

It seems to me that the above discussion sheds useful light on a range of debates in contemporary metaphysics. In particular, it highlights and clarifies an insufficiently recognised linguistic assumption which underlies a popular reductionist program. The program takes its lead from the arguments for a mind-brain identity theory advanced by Lewis and Armstrong in the 1960s. Lewis and Armstrong suggested independently that what is distinctive about mental states is their causal rôles. Pain for example is simply the state apt to be caused in certain ways (by pins or heat, for example), and to have certain effects (wincing, crying out, desiring to avoid, and so on). Given this conceptual analysis, the physicalist principle that all such effects are explicable in physical terms then yields the conclusion that mental states are physical states. Which physical states? Simply those that occupy the relevant causal rôles. As is well known, Lewis invokes Ramsey's technique for the elimination of theoretical terms in the service of this argument.

This approach has been taken to provide a general model for a reductionist materialism. The most explicit version of the general program I know is that spelt out

18 This last issue is central to the dispute between my view (see Price 1988, 1992) and that of Blackburn. In Blackburn's terms, I am someone who extends the quasi-realist project "all the way down." Blackburn's difficulty seems to me to be that non-global quasi-realism is in danger of being self-refuting: the better the quasi-realist does locally, the less reason there will be not to "go global". 
by Frank Jackson. ${ }^{19}$ Jackson takes the path of conceptual analysis followed by "Ramseyfication" to be the appropriate general strategy for metaphysics. It was that paper, and a more recent one by Lewis himself, ${ }^{20}$ that prompted me to try to formulate a concern I had already felt about the original argument for mind-body identity. It seemed to me that this reductionist program depended in any particular case on a crucial but usually unacknowledged assumption: roughly, the assumption that the reduced theory is doing the same linguistic job as the reducing theory. Unless this assumption is valid in the case in question, the proposed reduction would involve a kind of category mistake.

Thinking about how to make this point a vivid one, it seemed to me that a good strategy would be to point out that as it stood, the program could be applied in cases in which it seems quite clear that the concepts we start with are not in the same linguistic business as the physical descriptions the program would yield. By appealing to a case in which the relevant assumption would be quite implausible, I hoped to draw attention to the fact that it is also required in less contentious cases. Somewhat ironically, the case I had in mind was that of value. ${ }^{21}$

However, while I was wrong in thinking that no one would be tempted to apply Ramsey reduction to evaluative concepts, this actually makes very little difference to the relevance of the example. My argument is not a reductio, but simply requires a case in which it is easy to see that there is an issue as to whether the concepts whose reduction is contemplated belong to the same aspect of the linguistic enterprise as the physically kosher descriptions in terms of which the Ramsey program would cash them. Why is this obvious in the evaluative case? Simply because we are familiar with generations of evaluative non-factualists in philosophy, whose central thesis is that the rôle of evaluative judgements must be distinguished from that of ordinary descriptions.

Jackson and Pettit recognise the need for an assumption of this kind, and explicitly presuppose cognitivism. However, they appear to take for granted that this is an assumption to be cashed in semantic terms, as the thesis that evaluative judgements are genuinely "truth apt", or some such. The point I have emphasised above is that this seems to address the issue at the wrong level. A sophisticated non-factualist will simply deny that the interesting distinctions in language lie at this level. "Of course moral judgements are (minimally) truth apt", the cluey emotivist will say, "But this is quite compatible with my claim that such judgements are functionally distinct from natural

19 In "Armchair Metaphysics", presented at the Philosophy in Mind conference at UNSW in August 1992

20 "Reduction of Mind", to appear in S. Guttenplan, ed., A Companion to Philosophy of Mind, Blackwell, 1994.

21 Frank Jackson and Philip Pettit defend just such an approach to value in "How Values Motivate", delivered at the AAP Conference in Adelaide in July 1993. 
descriptions."

Thus the reductionist program appears to be driven by what amounts to a substantial semantic thesis, namely that the various bits of language in question have a common purpose - that of describing the world, saying how things are, or some such. It is only when coupled with this semantic thesis that physicalism provides a motivation for reductionism. However, while the effect of semantic minimalism is to deflate this thesis somewhat, so that it is no longer clear what the different parts of language are being held to have in common, the initial result seems to be something of a stand-off. We might say that in minimalist terms it isn't clear why we should want to be Ramsey reductionists, but neither is there any explicit objection to the application of the algorithm. The charge that reductionism may be guilty of a category mistake cannot itself be formulated in semantic terms, minimally construed.

The charge of possible category mistake can be formulated from the functional standpoint, however. It simply depends on an appreciation that semantic minimalism and uniformity is compatible with the existence of substantial diversity at the functional level. (Minimal descriptions need not be natural descriptions, as we put it earlier.) More importantly still, the functional standpoint threatens to undercut the motivation for reductionism: once we have an adequate explanation for the fact that the folk talk of Xs and Ys and Zs, an explanation which distinguishes these activities from what the folk are doing when they do physics, why should try to reduce the Xs and Ys and Zs to what is talked about in physics?

So it is the functional standpoint that matters in determining whether Ramsey reduction is appropriate. It is important to appreciate that the functional perspective is scientific, and naturalistic. Hence it can't be dismissed a priori-particularly by physicalists - and the reductionist program turns out to depend on an a posteriori theoretical thesis about language. Moreover, folk intuitions give us very little access to the matters addressed from this theoretical perspective. Such intuitions provide the explanandum - what we are after is a theory about the origins and functions of our folk intuitions - but not the explanans. So there really is no route into these issues than the hard one of standing back from the concepts in question and asking how they arise, and what functions they serve in the lives of the creatures who employ them. Despite its naturalism, this seems to be a thoroughly Wittgensteinian stance. ${ }^{22}$ In failing to notice

22 There are two importantly different explanatory stances here: one which seeks to explain a use of language "from the inside", allowing the explanans to include a certain shared phenomenological basis on which the discourse in question may be held to rest; and one which is more detached, in seeking to explain the use in question in more-or-less biological terms. As Kevin Mulligan has helped me to see, it may be that the former stance is very much more Wittgensteinian than the latter. If so then I part company with the Master at this point, in wanting to allow both. 
the importance of the issues addressed from this stance, reductionist metaphysics has put its money by default on the assumption that indicative discourse is functionally univocal. It doesn't seem to me to be a very good bet, and it is certainly not a bet to be made with one's eyes closed. The moral is that if you want to do metaphysics in this way, you had better think first about language - and you had better think about it in in Wittgensteinian terms! 


\section{BIBLIOGRAPHY}

Blackburn, S. (1971) 'Moral realism', in J. Casey (ed.) Morality and Moral Reasoning, London: Methuen.

— (1984) Spreading the Word, Oxford: Oxford University Press.

(1988) 'Attitudes and contents', Ethics 98, 3: 501-17.

Boghossian, P. (1990) 'The status of content', Philosophical Review 89: 157-84.

Cohen, J. (1977) The Probable and the Provable, Oxford: Oxford University Press.

Dummett, M. (1973) Frege: Philosophy of Language, London: Duckworth.

Frege, G. (1960) 'Negation', in P. Geach and M. Black (eds) Translations from the Philosophical Writings of Gottlob Frege, Oxford: Oxford University Press.

Geach, P. (1960) 'Ascriptivism', Philosophical Review 69: 221-225.

_ (1965) 'Assertion', Philosophical Review 74: 449-465.

Hare, R. M. (1971) Practical Inferences, London: Macmillan.

— (1976) 'Some confusions about subjectivity', in J. Bricke (ed.) Freedom and Morality: the Lindley Lectures Delivered at the University of Kansas, Lawrence: University of Kansas.

Horwich, P. (1990) Truth, Oxford: Basil Blackwell.

Kripke, S. A. (1982) Wittgenstein on Rules and Private Language, Oxford: Basil Blackwell.

McDowell, J. (1981) 'Anti-realism and the epistemology of understanding', in J. Bouveresse and H. Parret (eds) Meaning and Understanding, Berlin: W. de Gruyter.

Price, H. (1986) 'Conditional credence', Mind 95, 1: 18-36.

_ (1988) Facts and the Function of Truth, Oxford: Basil Blackwell.

_ (1990) 'Why “Not”?', Mind 99: 221-238.

(1992) 'Metaphysical pluralism', Journal of Philosophy 89, 8: 387-409.

Searle, J. (1962) 'Meaning and speech acts', Philosophical Review 71: 423-32.

-_ (1969) Speech Acts: an Essay in the Philosophy of Language, London: Cambridge University Press.

Wiggins, D. (1976) 'Truth, invention and the meaning of life', Proceedings of the British Academy 62: 331-78.

Wright, C. (1988) 'Realism, antirealism, irrealism, quasi-realism', Midwest Studies in Philosophy 12: 25-49.

_ (1993) 'Realism - the contemporary debate: whither now?', in J. Haldane and C. Wright (eds) Reality, Representation and Projection, Oxford: Oxford University Press. 